\title{
ANALISIS RETURN PORTOFOLIO YANG OPTIMAL PADA SAHAM LQ 45 YANG TERCATAT DI BURSA EFEK INDONESIA SELAMA PERIODE 2008-2010
}

\section{Jolanda Saputri dan Oktafalia Marisa Muzammil}

Email: oktafalia@yahoo.com

\section{Penulis}

Jolanda Saputri adalah alumni Universitas Bunda Mulia dengan bidang peminatan Manajemen Keuangan.

Oktafalia adalah staf pengajar di Universitas Bunda Mulia dengan peminatan pada bidang Kuantitatif, Keuangan, dan Perbankan.

\section{Abstract}

This research aimed to analyze the optimal portfolio return and the change in IHSG to changes in stock prices the securities sector. The purpose of this study is the author wanted to determine the effect of the transaction value of the securities sector stock price changes. The method used is the Sharpe Model, Single Index Model, and using Microsoft Office Excel. The result of this research is the only portfolio on the agricultural sector able to generate a positive return. Conclusions of this research, there were 12 companies included in the the optimal portfolio in LQ45 and agricultural sectors only have return rate postitif of 19:16\% and the risk by $5.92 \%$.

\section{Key Words}

Return, Risk, Single Indeks Model, and Sharpe Model

\section{PENDAHULUAN}

Indeks LQ 45 menggambarkan pertumbuhan harga saham yang tergolong pada kelompok tersebut. Pada awal 2003, kelompok indeks harga saham LQ 45 pada posisi 87,8 dan 30 April 2004 pada posisi 170,6. Berarti, kenaikan atau return saham pada 
waktu tersebut sebesar 72,8 poin atau 82,9\%. Keseluruhan indeks harga saham gabungan (IHSG) dari posisi 409,1 menjadi 783,4 atau naik 91,4\%. Hasil analisis statistik menunjukkan, perubahan harga saham pada LQ 45 bisa sebagai faktor penjelas (koefisien determinasi) terhadap perubahan IHSG. Kenaikan atau penurunan harga saham pada LQ 45 akan berpengaruh signifikan terhadap kenaikan atau penurunan IHSG juga sebaliknya.

Saham pada kelompok LQ 45, tergolong saham pilihan yang baik. Namun demikian, keputusan berinvestasi tidak hanya memenuhi kriteria baik, tetapi juga benar. Keputusan investasi pada LQ 45 baik dan benar, ketika pasar berada pada kondisi yang baik. Faktor politik saat ini, merupakan faktor kunci bursa di Indonesia. (Http://www.yahoo.finance.com)

Hakikat dari pembentukan portofolio yang efisien dan optimal adalah untuk mengurangi risiko dengan cara diversifikasi saham, yaitu mengalokasikan sejumlah dana investor pada berbagai alternatif investasi yang berkorelasi negatif agar dana yang dikeluarkan oleh investor dapat menghasilkan pengembalian yang optimal.

Untuk membentuk suatu portofolio optimal dapat menggunakan Model Indeks Tunggal (Single Index Model). Sedangkan untuk menentukan saham yang optimal dapat menggunakan Metode Sharpe. Model indeks tunggal didasarkan pada pengamatan bahwa harga dari suatu sekuritas berfluktuasi searah dengan indeks pasar. Secara khusus dapat diamati bahwa kebanyakan saham cenderung mengalami kenaikan harga jika indeks harga saham naik. Kebalikannya juga benar, yaitu jika indeks harga saham turun, kebanyakan saham mengalami penurunan harga. Hal ini menyarankan bahwa returnreturn dari sekuritas mungkin berkolerasi karena adanya reaksi umum (common response) terhadap perubahan-perubahan nilai pasar.

Asumsi-asumsi dari model indeks tunggal mempunyai implikasi bahwa sekuritassekuritas bergerak bersama-sama bukan karena efek di luar pasar, melainkan karena mempunyai hubungan yang umum terhadap indeks pasar yang searah dengan perubahan IHSG. Model indeks tunggal ini dapat diterima dan mewakili kenyataan sesungguhnya tergantung dari seberapa besar asumsi-asumsi ini realistis.

Investor juga harus dapat menentukan jenis saham apa yang mempunyai karakteristik searah dengan perubahan IHSG misalnya indeks saham LQ-45, hal ini agar 
investor mendapatkan pengembalian yang sesuai dengan harapan dan dengan risiko yang sesuai. Saham-saham yang membentuk LQ-45 adalah saham-saham yang cenderung stabil karena saham-saham tersebut termasuk saham-saham yang mudah diperjualbelikan baik dalam kondisi pasar lemah maupun kuat, dengan mudahnya saham-saham LQ-45 diperjual-belikan maka akan dapat menunjukkan suatu portofolio yang optimal antara return dan risiko yang diharapkan.

Berdasarkan latar belakang tersebut, maka penulis tertarik untuk mengadakan penelitian dengan judul: "Analisis Return Portofolio yang Optimal Pada Saham LQ-45 yang Tercatat di Bursa Efek Indonesia selama periode 2008-2010.

\section{TUJUAN PENELITIAN}

1. Untuk mengetahui saham apa saja yang dapat dibentuk menjadi portofolio optimal pada saham yang tercatat di Indeks LQ-45.

2. Untuk mengetahui tingkat pengembalian dan tingkat risiko portofolio saham yang tercatat di Indeks LQ-45.

\section{TINJAUAN PUSTAKA}

\section{Definisi LQ 45}

Indeks LQ 45 adalah nilai kapitalisasi pasar dari 45 saham yang paling likuid dan memiliki nilai kapitalisasi yang besar hal itu merupakan indikator likuidasi. Indeks LQ 45, menggunakan 45 saham yang terpilih berdasarkan Likuiditas perdagangan saham dan disesuaikan setiap enam bulan (setiap awal bulan Februari dan Agustus).

Faktor -faktor yang berperan dalam pergerakan Indeks LQ 45, yaitu :

1. Tingkat suku bunga SBI sebagai patokan (benchmark) portofolio investasi di pasar keuangan Indonesia,

2. Tingkat toleransi investor terhadap risiko, dan

3. Saham - saham penggerak indeks (index mover stocks) yang notabene merupakan saham berkapitalisasi pasar besar di BEI.

Tujuan indeks LQ 45 adalah sebagai pelengkap IHSG dan khususnya untuk menyediakan sarana yang obyektif dan terpercaya bagi analisis keuangan, manajer investasi, investor 
dan pemerhati pasar modal lainnya dalam memonitor pergerakan harga dari saham-saham yang aktif diperdagangkan.

\section{Hasil Penelitian Terdahulu}

Penelitian tentang pembentukan portofolio optimal pernah dilakukan oleh Kurniawan pada tahun 2003 dengan judul "Analisis Pembentukan Portofolio Optimal dalam Rangka Pemilihan Saham di Bursa Efek Jakarta”, dengan menggunakan metode SIM adalah: Portofolio optimal yang terdiri dari 6 saham dengan return ekspektasi portofolio sebesar 0,04670 dan rata-rata varian portofolio 0,01148 dengan komposisi proporsi saham yang membentuk portofolio optimal terdiri dari Bimantara Tbk. 48,782\%, Bank Central Asia Tbk. 8,307\%, Centrin Online Tbk. 4,244\%, Unilever Tbk. 24,710\%, Telekomunikasi Indonesia Tbk. 12,234\%, dan Jakarta International Hotel and Developer Tbk sebesar $1,722 \%$.

\section{Saham}

Pengertian Saham

Menurut Jeff Madura (2006), saham adalah surat bukti atau sertifikat yang mewakili kepemilikan seseorang dalam suatu perusahaan yang menerbitkan sertifikat tersebut.

\section{Pasar Modal}

\section{Pengertian Pasar Modal}

Pasar modal pada umumnya adalah tempat atau sarana bertemunya antara permintaan dan penawaran atas instrument keuangan jangka panjang, umumnya lebih dari 1 (satu) tahun. Hukum mendifinisikan pasar modal sebagai "kegiatan yang bersangkutan dngan penawaran umum dan perdagangan efek, perusahaan publik yang berkaitan dengan efek yang diterbitkannya, serta lembaga dan profesi yang berkaitan dengan efek". (http://hdl.handle.net/10364/671)

\section{Bursa Efek}

Menurut Tjiptono Darmadji dan Hendy Fakhrudin (2006), Bursa efek adalah lembaga/perusahaan yang menyelenggarakan/menyediakan fasilitas sistem (pasar) untuk mempertemukan penawaran jual dan beli efek antar bebagai perusahaan/perorangan yang 
terlibat dalam tujuan perdagangan efek perusahaan-perusahaan yang telah tercatat di bursa efek.

\section{Reksadana}

Reksadana merupakan terjemahan dari mutual fund. Bagi masyarakat Indonesia, meskipun reksada bukan hal baru, tetapi kurang popular, sehingga kurang menarik bagi investor. Di Indonesia, lembaga reksadana dipelopori oleh PT. Danareksa, sebuah BUMN (Badan Usaha Milik Negara) dibawah kontrol departemen keuangan.

\section{Indeks Harga Saham}

Menurut James H. Lorie, Peter Dodd dan Mary Hamilton Kimpton, (2005) Indeks harga saham merupakan barometer kesehatan ekonomi suatu negara dan sebagai landasan analisis statistik atas kondisi pasar terakhir. Indeks harga saham gabungan adalah gabungan dari indeks harga saham individu dan prinsipnya tidak berbeda dengan indeks harga saham, hanya saja dalam perhitungan indeks harga saham gabungan kita harus menjumlahkan seluruh harga saham yang ada (listing).

\section{Portofolio}

Menurut Fabozzi (2007) untuk mengurangi kerugian/ risiko investasi maka investor dapat berinvestasi dalam berbagai jenis saham dengan membentuk portofolio.

\section{Model Indeks Tunggal dan Metode Sharpe}

Ada 3 parameter yang dapat digunakan untuk mengukur kinerja portofolio yang dikembangkan oleh William Sharpe, Jack Treynor, dan Michael Jensen. Ketiga pengukuran kinerja ini dinamakan ukuran kinerja Sharpe, kinerja Treynor dan kinerja Jensen. Ketiga pengukuran kinerja tersebut mengasumsikan adanya hubungan linear antara pengembalian (return) portofolio dengan pengembalian dari beberapa indeks pasar. Ketiga model tersebut mendasarkan analisisnya pada return masa lalu untuk memprediksikan return dan risiko masa datang kata Samsul (2006). 
Rumus dari Metode Index Tunggal :

$\square \mathrm{RM}+\mathrm{e} \square+\beta \square \mathrm{R} 1$

$=\alpha$

Rumus dari Metode Sharpe :

$$
\mathrm{SM}=\frac{(\mathrm{R})-(\mathrm{RF})}{\Sigma}
$$

\section{KERANGKA PEMIKIRAN}

Dalam penelitian ini, penulis akan menganalisis mengenai kriteria, subkriteria dan alternatif yang sudah ditentukan

\section{GAMBAR 1}

\section{KERANGKA PEMIKIRAN}

Analisa portofolio yang optimal dengan menggunakan

SIM dan Shrape Model

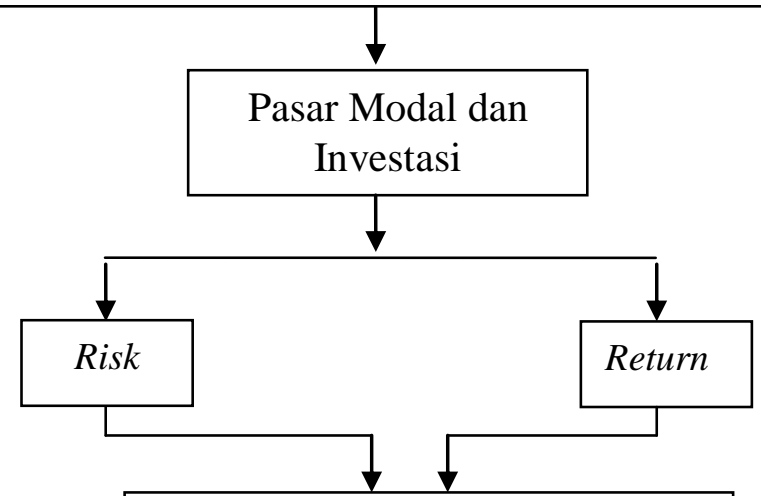

Diversifikasi dan variable yang mempengaruhi pmbentukan

portofolio optimal

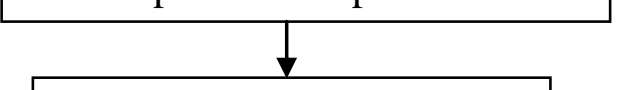

Saham-Saham portofolio optimal (saham LQ 45)

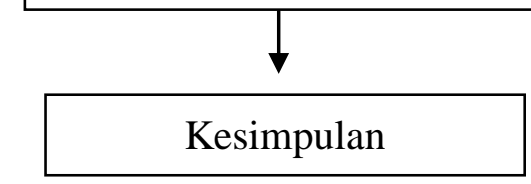

Sumber : diolah penulis 


\section{METODOLOGI PENELITIAN}

\section{Jenis Penelitian}

Dalam penelitian ini, penulis menggunakan jenis penelitian statistik deskriptif, yaitu untuk memberikan gambaran atau deskripsi suatu data yang dilihat dari nilai rata-rata (mean), standar deviasi, varian, maksimum, minimum, sum, range, kurtoris, dan skewness (kemencangan distribusi). Ghozali (2007).

Rancangan yang digunakan dalam penelitian ini adalah penelitian deskriptif karena penelitian ini menggambarkan dan menjelaskan pengaruh dari variable independent (SIM dan Metode sharpe) terhadap variable dependen (nilai perusahaan). Penelitian ini bersifat kuantitatif.

\section{Teknik Pengumpulan Data}

Metode pengumpulan data yang digunakan dalam penyusunan proposal ini adalah data sekunder yaitu data atau informasi yang telah dikumpulkan oleh pihak lain. Dalam hal ini, peneliti hanya bertindak sebagai pemakai data atau informasi terkait yang telah ada sebelumnya yang langsung diperoleh penulis melalui media prantara.

Data tersebut berupa closing price setiap perusahaan yang termasuk dalam LQ 45 selama tahun $2008-2010$.

\section{Populasi dan Sampel}

Populasi merupakan keseluruhan unsur yang menjadi subjek suatu penelitian. Populasi yang digunakan dalam penelitian ini adalah seluruh perusahaan yang termasuk dalam LQ 45. Sampel dari penelitian ini adalah perusahaan-perusahaan yang termasuk dalam LQ 45 yang terdaftar di BEI selama periode 2008-2010. Pengambilan sampel dilakukan dengan cara purposive sampling. Menurut Cooper dan Schindler dalam Suhartono (2006), purposive sampling adalah metode pengambilan sampel yang disesuaikan dengan syarat - syarat tertentu. Kriteria pemilihan sampel adalah :

1. Perusahaan yang termasuk dalam LQ 45 yang terdaftar di BEI selama periode $2008-2010$. 
2. Perusahaan yang konsisten selalu berada dalam LQ 45 selama periode $2008-2010$.

3. Sektor yang dibentuk sebagai portofolio paling tidak berisikan lebih dari satu perusahaan.

\section{Metode Analisis}

Dalam penelitian metode analisis yang digunakan oleh penulis antara lain meliputi :

\section{Single Indeks Model}

$$
\begin{aligned}
& \square \mathrm{RM}+\mathrm{e} \square+\beta \square \mathrm{R} 1 \\
& =\alpha
\end{aligned}
$$

Dimana dalam hal ini :

$\square \mathrm{R} \quad=$ Tingkat keuntungan suatu saham

$\square \alpha \quad=$ Bagian dari tingkat keuntungan saham I yang tidak dipengaruhi oleh perubahan pasar. Variabel ini merupakan variabel yang acak.

$\mathrm{Rm}=$ Tingkat keuntungan indeks pasar. Variabel ini merupakan variable yang acak.

$\square \mathrm{e} \quad=$ Tingkat error

Untuk menghitung return dan resiko saham

Return saham dapat dihitungan dengan rumus :

\section{Dimana :}

$$
\text { Return }=\frac{\mathrm{Pt}-\mathrm{Pt}-1}{\mathrm{Pt}-1}
$$

Pt = harga saham periode $\mathrm{t}$

Pt-1 = harga saham periode sebelumnya

Return Ekspektasi saham dapat dihitung dengan rumus :

Dimana :

$$
\mathrm{E}(\mathrm{Ri})=\frac{\substack{\mathrm{N} \\ \sum \mathrm{R}=1}}{\mathrm{~N}}
$$


$\mathrm{E}\left(\mathrm{R}_{\mathrm{i}}\right)=$ Tingkat keuntungan yang diharapkan dari investasi

$\mathrm{R}_{\mathrm{ij}} \quad=$ Return saham $\mathrm{i}$ periode $\mathrm{j}$

$\mathrm{N}=$ Jumlah periode

Risiko saham dapat dihitung dengan rumus :

Dimana :

$$
\sigma i^{2}=\sum_{j=1}^{N} \mathrm{~N}
$$

$\sigma \mathrm{i}^{2}=$ Varian

Menghitung return dan resiko pasar

Return pasar (IHSG) dapat dihitumg dengan rumus :

Dimana :

$$
\mathrm{Rm}, \mathrm{t}=\frac{\mathrm{IHSGt}-\text { IHSGt-1 }}{\text { IHSGt-1 }}
$$

$\mathrm{Rm}, \mathrm{t}=$ Return pasar periode $\mathrm{t}$

IHSGt $=$ IHSG periode $\mathrm{t}$

IHSGt-1 = IHSG periode sebelumnya

Return ekspektasi pasar dapat dihitung dengan rumus :

\begin{aligned} & $\mathrm{E}(\mathrm{Rm})= \begin{array}{l}\mathrm{N} \\ \mathrm{t}=1 \\ \mathrm{~N}\end{array} \\ &$\hline\end{aligned}

Dimana :

$\mathrm{E}(\mathrm{Rm}) \quad=$ Return ekspektasi pasar

Resiko pasar dapat dihitung dengan menggunakan rumus :

$$
\text { Dimana : } \quad \mathrm{m}^{2} \quad=\text { Varian pasar } \quad \begin{gathered}
\mathrm{N} \mathrm{m}^{2}=\sum_{\mathrm{t}=1}^{\mathrm{N}[(\mathrm{Rm}, \mathrm{t})-\mathrm{E}(\mathrm{Rm})]^{2}} \mathrm{~N} \\
\end{gathered}
$$


Menghitung Beta dan Alpha sekuritas

Beta sekuritas dapat dihitung dengan rumus :

$$
\beta i=\frac{\sigma i \mathrm{M}}{\sigma^{2} \mathrm{M}}
$$

Alpha sekuritas dapat dihitung dengan rumus :

$$
E(R i)=\alpha i+\beta i . E(R m)
$$

Menghitung kesalahan residu dan varian dari kesalahan residu

Kesalahan residu dapat dihitung dengan cara :

Dimana :

$$
\mathrm{Ri}=\alpha \mathrm{i}+\beta \mathrm{i} \cdot \mathrm{Rm}+\mathrm{ei}
$$

ei $=$ Kesalahan residu

Varian dari kesalahan residu dapat dihitung dengan cara :

$$
\sigma \mathrm{i}^{2}=\beta \mathrm{i}^{2} . \sigma \mathrm{m}^{2}+\sigma e \mathrm{i}^{2}
$$

Dimana :

$\sigma e i^{2}=$ varian dari kesalahan residu

\section{Menentukan portofolio optimal}

(1). Menghitung excess return to beta

$$
\mathrm{ERBi}=\frac{\mathrm{E}(\mathrm{Ri})-\mathrm{EBR}}{\beta \mathrm{i}}
$$

Dimana :

ERBi = excess return to beta sekuritas ke-i 
EBR = return aktiva bebas risiko

(2). Menentukan besarnya titik pembatas

Besarnya titik pembatas ini dapat ditentukan dengan langkah-

langkah sebagai berikut :

1. Urutkan sekuritas - sekuritas berdasarkan nilai ERB

terbesar ke ERB terkecil. Sekuritas - sekuritas dengan nilai

ERB terbesar merupakan kandidat unuk dimasukan ke dalam portofolio optimal.

2. Hitung nilai Ai dan Bi untuk masing - masing sekuritas kei sebagai beikut :

$$
\mathrm{Ai}=\frac{[\mathrm{E}(\mathrm{Ri})-\mathrm{RBR}]-\beta \mathrm{i}}{\sigma e \mathrm{i}^{2}}
$$

Dan

$$
\mathrm{Bi}=\frac{\beta \mathbf{i}^{2}}{\sigma \mathrm{ei} \mathrm{i}^{2}}
$$

3. Menghitung $\mathrm{Ci}$

$$
\mathrm{Ci}={\frac{\sigma \mathrm{M}^{2} \sum \mathrm{J}=1}{\mathrm{i}} \mathrm{Ai}}_{1+\sigma^{2} \sum \mathrm{Bi}}
$$

4. Besarnya cut-off point $\left(\mathrm{C}^{*}\right)$ adalah nilai $\mathrm{C}_{\mathrm{i} \text { yang terbesar. }}$

5. Sekuritas-sekuritas yang membentuk portofolio optimal adalah sekuritas-sekuritas yang mempunyai nilai ERB lebih besar atau sama dengan nilai ERB di titik C*. Sekuritassekuritas yang mempunyai ERB lebih kecil dengan ERB titik $C^{*}$ tidak diikutsertakan dalam pembentukan portofolio optimal. 
(3). Menentukan besarnya proporsi masing- masing sekuritas tersebut di dalam portofolio optimal. Besarnya proporsi untuk sekuritas ke i adalah sebesar :

$$
\mathrm{Wi}=\frac{\mathrm{Xi}}{\mathrm{k}} \quad \Sigma \mathrm{Xi}
$$

Dimana :

Wi $=$ Proporsi sekuritas ke-i

$\mathrm{K}$ = Jumlah sekuritas di portofolio optimal

Dengan nilai Xi adalah :Dimana :

$$
\mathrm{Xi}=\frac{\beta \mathrm{i}}{\sigma \mathrm{e}^{2}}\left(\mathrm{ERBi}-\mathrm{C}^{*}\right)
$$

6. Menentukan Return dan risiko portofolio

(1). Menghitung return ekspektasi portofolio

1. Beta dari portofolio $\left(\beta_{\mathrm{p}}\right)$ merupakan rata-rata tertimbang dari

Beta masing-masing sekuritas $\left(\beta_{p}\right)$ :

$$
\beta \mathrm{p}=\sum_{\mathrm{i}=1}^{\mathrm{n}} \mathrm{Wi} \beta \mathrm{i}
$$

2. Alpha dari portofolio $\left(\alpha_{\mathrm{p}}\right)$ juga merupakan rata-rata tertimbang dari Alpha tiap-tiap sekuritas $\left(\alpha_{\mathrm{p}}\right)$ :

$\alpha p=\sum_{i=1}^{n}$ Wi $\alpha \mathrm{i}$


Dengan mensubstitusikan karakteristik ini, yaitu $\beta_{\text {p.dan }} \alpha_{p}$, maka return ekspektasi portofolio adalah sebagai berikut :

$$
\mathrm{E}(\mathrm{Rp})=\alpha p+\beta p \mathrm{E}(\mathrm{RM})
$$

(2). Menghitung Risiko portofolio varian dari portofolio adalah sebesar :

$$
\sigma \mathrm{p}^{2}=\beta \mathrm{p}^{2} \cdot \sigma \mathrm{M}^{2}+(\Sigma \mathrm{Wi} \sigma \mathrm{ei})^{2}
$$

\section{Sharpe Model}

$$
\mathrm{SM}=\frac{(\mathrm{Rp})-(\mathrm{Rf})}{\sigma \mathrm{p}}
$$

Dimana :

$\mathrm{SM}=$ Rasio Sharpe

$\mathrm{Rp} \quad=$ Rata-rata return portofolio yaitu capital gaint, biaya jual beli dan biaya administrasi reksadana.

Rf $\quad=$ Risk Free rate $(\mathrm{SBI})$

$\sigma \mathrm{p}=$ Deviasi standar return portofolio sebagai tolak ukur risiko

\section{HASIL DAN ANALISIS DATA}

\section{Portofolio Optimal Berdasarkan Model Indeks Tunggal}

Metode yang digunakan dalam pembentukan portofolio optimal dari 21 saham ini adalah model indeks tunggal. Dalam pemilihan saham-saham yang akan dimasukan dalam suatu portofolio, perlu adanya suatu kriteria tertentu. Pada model indeks tunggal, langkah pertama yang harus dilakukan adalah menhitung nilai ERB (excess return to beta) untuk masing-masing sekuritas. Dalam menghitung ERB dibutuhkan tingkat pengembalian bebas risiko (RBR). Tingkat pengembalian bebas risiko dihitung berdasarkan tingkat suku bunga Sertifikat Bank Indonesia (SBI). Dalam tugas akhir ini, karena harga saham 
yang digunakan adalah harga saham per enam bulan, maka return bebas risiko yang digunakan dalam satuan enam bulanan.

Berikut ini adalah tabel yang menunjukkan nilai ERB dari masing-masing sekuritas.

Tabel 1

Hasil Perhitungan Excess Return To Beta (Erb) yang Tercatat di Bursa Efek

Indonesia Periode 2008 - 2010

\begin{tabular}{|c|c|}
\hline Kode & ERB \\
\hline AALI & 0.0555 \\
\hline ANTM & 0.1009 \\
\hline BBCA & -0.2339 \\
\hline BBNI & 0.0576 \\
\hline BBRI & 0.0206 \\
\hline BDMN & -0.0419 \\
\hline BMRI & 0.056 \\
\hline BNBR & -0.1538 \\
\hline BTEL & 0.0492 \\
\hline BUMI & 0.0933 \\
\hline ENRG & 0.0845 \\
\hline INCO & 0.1641 \\
\hline ISAT & 0.2504 \\
\hline MEDC & -0.0159 \\
\hline PGAS & -0.064 \\
\hline PTBA & 0.072 \\
\hline TINS & 0.0648 \\
\hline TLKM & 0.313 \\
\hline TRUB & -0.2592 \\
\hline UNSP & 0.0214 \\
\hline UNTR & 0.0762 \\
\hline
\end{tabular}

Sumber : Data sekunder diolah penulis tahun 2011

Langkah selanjutnya adalah mengurutkan sekuritas - sekuritas berdasarkan nilai ERB terbesar ke nilai ERB terkecil. Portofolio optimal akan terdiri dari saham-saham yang mempunyai nilai ERB yang tinggi. Nilai Cut of point (Ci) akan digunakan sebagai 
batasan suatu saham masuk dalam portofolio. Besarnya nilai Cut of Point adalah nilai Ci terbesar, sedangkan sekuritas yang membentuk portofolio optimal adalah sekuritassekuritas yang mempunyai nilai ERB lebih besar atau sama dengan nilai ERB dititik Ci

Tabel 2

Perbandingan Nilai Erb Dengan Ci Masing-Masing Saham yang Tercatat di Bursa Efek Indonesia Periode 2008 - 2010

\begin{tabular}{|c|c|c|c|}
\hline Kode & ERB & & Ci \\
\hline
\end{tabular}

\begin{tabular}{|c|c|c|c|}
\hline TLKM & 0.313 & $<$ & 0.8801 \\
\hline ISAT & 0.2504 & $<$ & 7.3294 \\
\hline INCO & 0.1641 & $<$ & 0.1764 \\
\hline ANTM & 0.1009 & $>$ & -0.2128 \\
\hline BUMI & 0.0933 & $>$ & -0.1185 \\
\hline ENRG & 0.0845 & $>$ & -0.3634 \\
\hline UNTR & 0.0762 & $>$ & -0.2885 \\
\hline PTBA & 0.072 & $>$ & -0.2215 \\
\hline TINS & 0.0648 & $>$ & -0.1517 \\
\hline BBNI & 0.0576 & $>$ & -5.0949 \\
\hline BMRI & 0.056 & $<$ & 2.9545 \\
\hline AALI & 0.0555 & $>$ & -1.6736 \\
\hline BTEL & 0.0492 & $<$ & 0.8883 \\
\hline UNSP & 0.0214 & $>$ & -0.4283 \\
\hline BBRI & 0.0206 & $>$ & -1.4007 \\
\hline MEDC & -0.0159 & $<$ & 2.9603 \\
\hline BDMN & -0.0419 & $<$ & 1.0504 \\
\hline PGAS & -0.064 & $>$ & -0.3467 \\
\hline BNBR & -0.1538 & $<$ & 311.2447 \\
\hline BBCA & -0.2339 & $>$ & -5.2264 \\
\hline TRUB & -0.2592 & $<$ & 0.9509 \\
\hline
\end{tabular}

Sumber : Data sekunder diolah penulis tahun 2011

Cut of $f$ point $(\mathrm{Ci})$ yang merupakan nilai $\mathrm{Ci}$ tertinggi berada pada angka 311.2447 atau pada saham BNBR (Bakrie dan Brothers Tbk ). Dari tabel diatas dapat diketahui bahwa ada 12 saham yang optimal. Saham-saham tersebut adalah ANTM, BUMI, ENRG, UNTR, PTBA, TINS, BBNI, AALI, UNSP, BBRI, PGAS, dan BBCA. . Metode Sharpe 
Setelah mengetahui saham - saham apa saja yang optimal kemudian kita memisahkannya berdasarkan sektor, maka dari itu hasil yang diperoleh adalah

\section{Tabel 3}

Perusahaan Berdasarkan Sektor yang Tercatat di Bursa Efek Indonesia

Periode 2008 - 2010

\begin{tabular}{|c|c|}
\hline Sektor & Kode \\
\hline \multirow[b]{2}{*}{ Pertanian } & AALI \\
\hline & UNSP \\
\hline \multirow[b]{7}{*}{ Pertambangan } & ANTM \\
\hline & BUMI \\
\hline & ENRG \\
\hline & INCO \\
\hline & MEDC \\
\hline & PTBA \\
\hline & TINS \\
\hline \multirow[b]{5}{*}{ Perbankan } & $\mathrm{BBCA}$ \\
\hline & BBNI \\
\hline & BMRI \\
\hline & BBRI \\
\hline & BDMN \\
\hline \multirow[b]{5}{*}{ Insfrastruktur } & BTEL \\
\hline & ISAT \\
\hline & PGAS \\
\hline & TLKM \\
\hline & TRUB \\
\hline \multirow[b]{2}{*}{ Perdagangan dagang dan jasa } & BNBR \\
\hline & UNTR \\
\hline
\end{tabular}

Sumber : Data sekunder diolah penulis tahun 2011 
Tabel 4

Risiko Dari Model Sharpe Berdasarkan Sektor yang Tercatat di Bursa Efek Indonesia Periode 2008-2010

\begin{tabular}{|c|c|}
\hline Sektor & $\mathbf{\Sigma} \mathbf{p}$ \\
\hline Pertanian & 0.0592 \\
\hline Pertambangan & 0.0218 \\
\hline Perbankan & 0.0881 \\
\hline Infrastruktur & 0.0504 \\
\hline Perdagangan dagang dan jasa & 0.0076 \\
\hline
\end{tabular}

Sumber : Data sekunder diolah penulis tahun 2011

Tabel 5

Hasil Perhitungan Model Sharpe Berdasarkan Sektor yang Tercatat di Bursa Efek Indonesia Periode 2008 - 2010

\begin{tabular}{|c|c|}
\hline Sektor & SM \\
\hline Pertanian & 0.1916 \\
\hline Pertambangan & -0.0067 \\
\hline Perbankan & -0.0389 \\
\hline Infrastruktur & -0.0115 \\
\hline Perdagangan dagang dan jasa & -0.2354 \\
\hline
\end{tabular}

Sumber : Data sekunder diolah penulis tahun 2011

Dapat dilihat dari hasil di atas bahwa sektor yang memberikan pengembalian yang positif hanyalah sektor pertanian. Maka dari itu sektor pertanian inilah yang return portofolionya dapat menutupi risiko yang ada.

\section{Analisa Portofolio Optimal Menggunakan Model Indeks Tunggal dan Metode Sharpe}

Dalam pembentukan portofolio, investor selalu ingin memaksimalkan return yang diharapkan dengan tingkat risiko tertentu yang bersedia ditanggungnya, atau mencari portofolio yang menawarkan risiko terendah dengan tingkat return tertentu. Maka para investor harus mampu untuk menentukan pilihan yang tepat saham-saham mana saja yang harus dibeli sehingga terbentuk portofolio optimal. Untuk itu dilakukan penilaian saham. Penilaian yang dilakukan di sini yaitu dengan analisis teknikal. Analisis teknikal 
mendasarkan pada pergerakkan harga saham dari waktu ke waktu. Jadi, untuk mengetahui pola pergerakan harga saham di masa datang dengan berdasarkan pada observasi pergerakkan harga saham di masa lalu.

Data-data yang dipakai oleh para analis adalah data-data pasar (market data) yang bersifat historis, seperti harga saham dan IHSG. Bagi para analis teknikal, data-data pasar ini sudah mencukupi sebagai dasar pembuatan keputusan investasi, sehingga tidak perlu lagi tergantung pada data laporan keuangan.

Dari analisa yang telah dilakukan, didapatkan hasil bahwa sektor yang memiliki nilai positif dan return portofolionya dapat menutupi risiko yang ada adalah sektor pertanian.

\section{KESIMPULAN DAN SARAN}

\section{Kesimpulan}

Berdasarkan analisis dan pembahasan pada bab sebelumnya, dapat diambil kesimpulan bahwa pembentukkan potofolio optimal pada tahun 2008- 2010 dari 21 saham LQ-45 yang kontiniyu masuk dalam indeks LQ-45, terdapat 12 saham yang membentuk portofolio yang optimal dan satu sektor yang memiliki tingkat pengembalian yang positif dan mampu menutupi risiko yang ada, yaitu sektor pertanian. Dan ke 12 saham tersebut sebagai berikut :

1. Saham-saham yang masuk menjadi portofolio optimal pada saham yang tercatat di indeks LQ-45 dengan menggunakan metode Sharpe, adalah ANTM, BUMI, ENRG, UNTR, PTBA, TINS, BBNI, AALI, UNSP, BBRI, PGAS, BBCA.

2. Tingkat pengembalian dan tingkat risiko portofolio optimal saham yang tercatat di LQ-45, adalah pertanian yaitu tingkat pengembalian returnnya sebesar 0.1916 atau $19.16 \%$, dan tingkat risikonya adalah 0.0592 atau $5.92 \%$.

Hal ini menunjukkan bahwa saham-saham yang tercatat di LQ-45 setelah di satukan dalam satu portofolio berdasarkan sektor ternyata tidak selalu memberikan return yang 
positif atau optimal, dengan kata lain kinerjanya menjadi relatif tidak maksimal disebabkan return portofolio tersebut tidak dapat menutupi risiko yang ada.

\section{Saran}

Dari penelitian ini, maka penulis menyarankan bahwa :

1. Investor sebaiknya membeli saham dalam bentuk portofolio pada Bursa Efek Indonesia karena portofolio pada sektor ini mampu memberikan return yang positif dengan kata lain return yang dihasilkan dapat menutupi risiko yang ada dibandingkan dengan portofolio dari ke empat sektor lainnya.

2. Masyarakat yang ingin berinvestasi dalam bentuk portofolio saham di pasar modal harus ikut mempertimbangkan perubahan IHSG selain kinerja perusahaan. Sekuritas yang berkaitan langsung dengan perdagangan saham seperti nilai transaksi saham.

\section{DAFTAR PUSTAKA}

Bodie, Kane dan Marcus, 2006, Investment (investasi), Buku 1 Edisi 6, Salemba Empat, Jakarta.

Eduardus Tandellin, 2007, Analisis Investasi dan Manajemen Portofolio, Edisi Pertama, BPFE, Yogyakarta.

Frank J, Fabozzi, 2007, Manajemen Investasi, Buku 2, Salemba Empat, Jakarta.

Jogiyanto, 2006, Teori Portofolio dan Analisis Investasi, BPFE, Yogyakarta.

Kammarudin Ahmad, 2006, Dasar-dasar Manajemen Investasi, Rineka Cipta, Jakarta.

Ramahdan, Syahril, 2008, Pasar Uang dan Pasar Modal, Jakarta.

Samsul, Mohamad, 2006, Pasar Modal \& Manajemen Portofolio, Erlangga, Surabaya.

Sentanoe Kertonegoro, 2005, Analisis dan Manajemen Investasi, Widya Perss, Jakarta.

Siamat, Dahlan, 2005, Manajemen Lembaga Keuangan, Edisi kelima, Fakultas Ekonomi Universitas Indonesia, Jakarta. 
Suad, Husnan, 2004, Dasar-dasar Teori Portofolio dan Analisis Sekuritas, Edisi keempat, UPP AMP YKPN, Yogyakarta.

William F. Sharpe, Gordon J. Alexander, dan Jeffery V. Bailey, 2007, Investasi,

http://hdl.handle.net/10364/671.

http://proquest.com , Ellin Raymond, Finance Definition, Packaging, Digest, Chicago :

Vol 12 edisi 3, 1 Juli 2009.

http://proquest.com, Ellin Raymond, Finance Definition, Packaging, Digest, Chicago :

Vol 15edisi 3, 1 Juli 2009.

Jilid 2, PT. Prenhalindo, Jakarta.

www.e-trading.com

www.finance.yahoo.com

www.idx.co.id 